\title{
Cell-derived Secretome for the Treatment of Renal Disease
}

\author{
Michael W. Kim, B.S. \\ In Kap Ko, Ph.D. \\ Anthony Atala, M.D. \\ James J.Yoo, M.D., Ph.D.* \\ Wake Forest Institute for Regenerative \\ Medicine, Wake Forest School of \\ Medicine, Medical Center Boulevard, \\ Winston-Salem, NC 27157, USA \\ *Corresponding author: \\ James J. Yoo, M.D, Ph.D. \\ Wake Forest Institute for Regenerative \\ Medicine, Wake Forest School of Medicine \\ Medical Center Boulevard, Winston-Salem, \\ North Carolina 27157, USA \\ Tel:+1-336-713-7294 \\ Fax: +1-336-713-7290 \\ E-mail:jyoo@wakehealth.edu
}

Received: 10 September 2019

Revised: 7 October 2019

Accepted: 12 October 2019

This is an open-access article distributed under the terms of the Creative Commons Attribution Non-Commercial License (http:// creativecommons.org/licenses/by-nc/4.0/) which permits unrestricted non-commercial use, distribution, and reproduction in any medium, provided the original work is properly cited.

Copyright (C) 2019 The Korean Society of Pediatric Nephrology
Kidney disease is a major global health issue. Hemodialysis and kidney transplantation have been used in the clinic to treat renal failure. However, the dialysis is not an effective long-term option, as it is unable to replace complete renal functions. Kidney transplantation is the only permanent treatment for end-stage renal disease (ESRD), but a shortage of implantable kidney tissues limits the therapeutic availability. As such, there is a dire need to come up with a solution that provides renal functions as an alternative to the current standards. Recent advances in cellbased therapy have offered new therapeutic options for the treatment of damaged kidney tissues. Particularly, cell secretome therapy utilizing bioactive compounds released from therapeutic cells holds significant beneficial effects on the kidneys. This review will describe the reno-therapeutic effects of secretome components derived from various types of cells and discuss the development of efficient delivery methods to improve the therapeutic outcomes.

Key words: Renal disease, Regenerative Medicine, Secretome therapy, Secretome delivery

\section{Introduction}

Recent developments in regenerative medicine have provided attractive solutions for the treatment of renal diseases. Several technologies developed in regenerative medicine have been applied to treat renal failure ${ }^{1-3)}$. Among the technologies, cell-based therapy has been primarily considered as a therapeutic intervention to provide renal functions ${ }^{1-3)}$. A commonly used approach in cell-based therapy is cell transplantation, where therapeutic cells are exogenously administered to achieve the repair. The cell transplantation approach using various cell types have resulted in reno-therapeutic outcomes in many pre-clinical ${ }^{1-3)}$ and clinical studies ${ }^{4)}$. For example, primary renal cells isolated from kidney tissues were introduced to improve renal functions from kidney diseases in a pre-clinical ${ }^{5)}$ and clinical study ${ }^{4}$. Similarly, various stem cells, including adult, fetal, embryonic, and induced pluripotent stem cells also have been extensively studied as therapeutic cell sources and demonstrated the beneficial therapeutic effects in renal failure ${ }^{6}$. While the cell transplantation approach has demonstrated promising outcomes, in terms of improvement of renal function, several safety issues still remain to be addressed prior to applying clinically. These include immune rejection, pulmonary 
embolism, and teratoma formation by uncontrolled proliferation of pluripotent stem cells ${ }^{7,8)}$. While cellular therapy has become a potential therapeutic modality for selected populations, its mode of action remains controversial. Many investigators believe that the effects of cell therapy may be primarily due to trophic factors secreted by the administered cells (secretomes). Consequently, research using cell-derived secretomes has been actively pursued in various areas, including the kidneys.

Secretome is generally referred to as the trophic factors present in conditioned medium of cell culture $(\mathrm{CM})^{9)}$, and is comprised of soluble and insoluble molecules enriched with bioactivity that is suitable for tissue regeneration. Several studies reported that exogenous delivery of secretomes resulted in therapeutic efficacy on the improvement of renal functions in pre-clinical and clinical studies ${ }^{10-13)}$. The therapeutic outcome by the secretome treatment is largely attributed to various secretome-derived bioactive compounds such as cytokines, chemokines and growth factors, lipids, free nucleic acids, and extracellular vesicles $(E V)^{14-16)}$. The important roles of the secretome compounds localized within the tissue injury site are believed to be angiogenesis, modulation of inflammatory, and inhibition of apoptosis of renal cells ${ }^{11)}$ (Fig. 1). In this article, we will review these secretome components and applications using various types of cell-derived secretomes for treatment of renal diseases (Table 1). Engineering platforms for efficient delivery of the secretomes will also be discussed (Table 1).

\section{Secretomes used for kidney applications}

\section{Mesenchymal stem cell (MSC)-derived secretome}

MSC is a stem cell type that is widely used in cell transplantation for tissue regeneration due to their availability in many tissue types and their ability to regenerate tissues for repair ${ }^{12,13)}$. The primary role of MSC underlying the regenerative mechanism following transplantation is known to enhance angiogenesis, induce anti-apoptosis, and modulate inflammation within the injured tissue ${ }^{11)}$. Several studies reported that the regenerative effects are mediated by paracrine actions via trophic factors secreted from the localized MSC into the injury site. For example, MSC infusion into the damaged kidney tissue facilitated the improvement of renal functions that are attributed to the pro-angiogenic capability. Pro-angiogenic soluble factors ${ }^{11,}$ ${ }^{17,18)}$, including vascular endothelial growth factor (VEGF), basic fibroblast growth factor (bFGF), placental growth factor (PGF) and monocyte chemoattraction protein 1 (MCP-1) were reported to improve vasculogenesis and angiogenesis of injured kidney ${ }^{19,20)}$. In one study, Rota C et al. reported that amniotic fluid-derived MSCs reduced cisplatin-induced renal injury and the reno-protective effect was significantly improved by the angiogenic capability of VEGF, stromal cell-derived factor-1 (SDF-1) and insulinlike growth factor-1 (IGF-1) ${ }^{21)}$. Moreover, another study reported by Takahashi et al. using an ischemic tissue model, VEGF and IGF-1 were found to exert anti-apoptotic effects on the improvement of tissue functions ${ }^{22)}$, indicating a possible therapeutic mechanism of MSC secretome-derived anti-apoptosis for the renal repair.

In addition to the angiogenic and anti-apoptotic effects of MSC-derived soluble factors, the anti-inflammatory function also contributes to the improvement of renal functions. Other soluble factors such as transforming growth factor-beta 1 (TGF- $\beta 1$ ), prostaglandin $\mathrm{E}_{2}\left(\mathrm{PGE}_{2}\right)$, nitric oxide (NO), interleukin-6 (IL-6) and indoleamine 2,3-dioxygenase (IDO) present in the MSC-derived secretome have demonstrated the immunomodulatory effects within the damaged tissue. These factors are believed to play a critical role in transforming of the macrophage phenotype to anti-inflammatory subsets and regulating the balance of T helper 1 cell and TH17 cell (pro-inflammatory)

Secretome

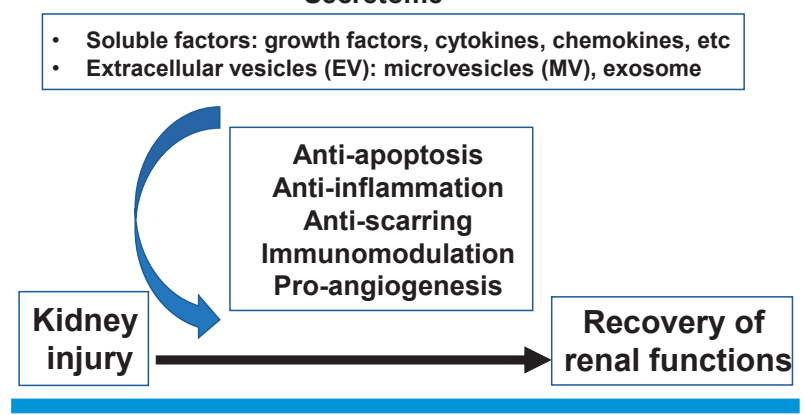

Fig. 1. Secretome therapy for treatment of renal disease. Cellsecreting molecules such as soluble factors and extracellular vesicles (EV) in the secretome contain therapeutic ability to recover the renal functions from the kidney injury. The possible mechanism underlying the beneficial effects can be explained by anti-apoptotic, anti-inflammatory, anti-scarring, immunomodulatory and pro-angiogenic property of the treated secretome into the damaged kidney. 
to $\mathrm{T}_{\mathrm{H}} 2$ cell and regulatory $\mathrm{T}$ cell (anti-inflammatory) ${ }^{23-25)}$. These findings have suggested that the immune-modulatory action through the factors support the improvement of renal function ${ }^{26)}$.

Based on the positive paracrine effects of the trophic factors released from MSC, several studies utilized MSCderived secretome to examine the therapeutic effects on kidney recovery. Abedi et al. administered human MSCsecretome via intraperitoneal injection to the gentamicininduced kidney injury and observed partial tissue regeneration $^{27)}$. In another study, da Silva et al. demonstrated the therapeutic outcomes of MSC-secretome treatment using a CKD model ${ }^{28}$. Secretome derived from rat MSCs was administered into a unilateral ureteral obstruction (UUO) model through the abdominal vena cava after total ligation of the left ureter. In this study, administration of MSCderived secretome improved fibrosis progression and factors involved in apoptosis, inflammation, cell proliferation, and epithelial-mesenchymal transition in rats subjected to $\mathrm{UUO}^{28}$. More recently, Liu et al. reported a possible tool of human MSC (hMSC) secretome for the treatment of a UUO kidney model ${ }^{29)}$. They collected human MSC secretome from human umbilical cord MSC culture (hMSCsecretome) and introduced through an intravenous injection, which resulted in improvement of renal functions. They believe that the therapeutic efficacy was likely mediated by reduced anti-apoptosis, inflammatory markers, and fibrosis progression as well as improvement of renal

Table 1. Cell Secretomes used for Kidney Applications

\begin{tabular}{|c|c|c|c|c|c|}
\hline Cells & Origin & Component & Delivery & Therapeutic effects (species; disease; functions) & References \\
\hline MSC & $\begin{array}{c}\text { Human } \\
\text { bone marrow }\end{array}$ & Whole secretome & I.P. & $\begin{array}{l}\text { Rats; Gentamicin-inducted AKI; injection time- } \\
\text { dependent function improvement }\end{array}$ & Abedi et al. ${ }^{27)}$ \\
\hline MSC & $\begin{array}{c}\text { Rat } \\
\text { bone marrow }\end{array}$ & Whole secretome & I.V. & $\begin{array}{l}\text { Rats; UUO; reduced fibrosis progression and renal } \\
\text { cell apoptosis }\end{array}$ & da Silva et al. ${ }^{28)}$ \\
\hline MSC & $\begin{array}{l}\text { Human } \\
\text { umbilical cord }\end{array}$ & Whole secretome & I.V. & $\begin{array}{l}\text { Rats; UUO; reduction in fibrosis progression, } \\
\text { inflammation and renal cell apoptosis, } \\
\text { proliferation of renal cells }\end{array}$ & Liu et al. ${ }^{29)}$ \\
\hline MSC & $\begin{array}{l}\text { Human } \\
\text { cord blood }\end{array}$ & EV from secretome & I.V. & $\begin{array}{l}\text { Clinical trials; CKD with 15-60 mg/ml/min in GFR; } \\
\text { amelioration of inflammatory immune reaction } \\
\text { and overall function improvement }\end{array}$ & Nassar et al..$^{80)}$ \\
\hline MSC & $\begin{array}{l}\text { Human } \\
\text { bone marrow }\end{array}$ & MV from secretome & I.V. & $\begin{array}{c}\text { Rats; IRl; inhibition of apoptosis and stimulation of } \\
\text { tubular cells }\end{array}$ & Gatti et al. ${ }^{40)}$ \\
\hline MSC & $\begin{array}{l}\text { Human } \\
\text { bone marrow }\end{array}$ & MV from secretome & I.V. & $\begin{array}{l}\text { SCID mice; rhabdomyolisis-induced AKI by } \\
\text { glycerol intramuscular injection; tubular cell } \\
\text { proliferation through horizontal transfer of mRNA }\end{array}$ & Bruno et al. ${ }^{38)}$ \\
\hline MSC & $\begin{array}{l}\text { Human } \\
\text { bone marrow }\end{array}$ & miRNA-let7c-EV & I.V. & $\begin{array}{c}\text { C57BL mice; UUO; anti-fibrotic function of miRNA } \\
\text { let7c-expression }\end{array}$ & Wang et al. ${ }^{49}$ \\
\hline Renal cells & Rat kidney & EV from tubular cells & I.V. & $\begin{array}{l}\text { Rats; ischemia; improved renal functions, reduced } \\
\text { tubular damages and fibrosis }\end{array}$ & Dominguez et al. ${ }^{53)}$ \\
\hline MSC & Human ESC & Whole secretome & I.V. & $\begin{array}{l}\text { Rats; } 5 / 6 \text { nephrectomy; inhibition of CKD } \\
\text { progression, improved tubular and glomerula } \\
\text { injury, no therapeutic effects using MSC-EV only. }\end{array}$ & van Koppen et al. ${ }^{55)}$ \\
\hline iPSC & Murine iPSC & Whole secretome & I.P. & $\begin{array}{c}\text { Rats; IRI; down-regulation of oxidative stress-related } \\
\text { pathway }\end{array}$ & Tarng et al. ${ }^{58)}$ \\
\hline EPC & $\begin{array}{c}\text { Human } \\
\text { peripheral blood }\end{array}$ & MV & I.V. & $\begin{array}{l}\text { Rats; IRI; reprogramming of host renal cells by } \\
\text { miRNA delivery in MV }\end{array}$ & Cantaluppi et al. ${ }^{61)}$ \\
\hline EPC & Human EPC & EV & I.V. & $\begin{array}{c}\text { Rats; experimental anti-Thy1.1 glomerulonephritis; } \\
\text { inhibition of antibody-and complement-mediated } \\
\text { injury of mesangial cells }\end{array}$ & Cantaluppi et al. ${ }^{62)}$ \\
\hline ESC & Mouse ESC & $\begin{array}{l}\text { Whole secretome } \\
\text { recovered by self- } \\
\text { assembled nanofiber }\end{array}$ & $\begin{array}{l}\text { I.P. delivery of } \\
\text { nanofiber hydrogel }\end{array}$ & $\begin{array}{c}\text { C57BL mice; LPS-induced AKI; reduced apoptosis } \\
\text { of renal cells }\end{array}$ & Wang et al. ${ }^{73)}$ \\
\hline PSC & Human & $\begin{array}{l}\text { Whole secretome } \\
\text { combined with PRP }\end{array}$ & $\begin{array}{l}\text { Intrarenal delivery of } \\
\text { PRP and secretome }\end{array}$ & $\begin{array}{l}\text { Rats; IRI; reduced apoptosis and improved } \\
\text { proliferation of renal cells }\end{array}$ & Yim et al..$^{77)}$ \\
\hline
\end{tabular}

Intraperitoneal injection (I.P.), intravenous injection (I.V.), Unilateral ureteral obstruction (UUO), chronic kidney disease (CKD), glomerular filtration rate (GFR), microvesicle (MV), ischemic-reperfusion injury (IRI), severe combined immunodeficiency (SCID), messenger RNA (mRNA), extracellular vesicle (EV), embryonic stem cell (ESC), placental stem cell (PSC), platelet rich plasma (PRP) 
cells proliferation.

While the whole secretome, which contains all factors secreted by cells, has been successfully used as a therapeutic cue for renal treatment, a number of studies attempted to use a specific compound derived from the secretome. Use of well-defined secretome factors would be more practical for clinical use, in terms of safety and minimizing regulatory concerns ${ }^{7}$. Extracellular vesicle (EV), as a compound of cell secretome, has been studied for therapeutic efficacy on renal treatment. EV is a broad term that describes membrane vesicles formed by various cell types that are released to the extracellular environment ${ }^{30)}$ and plays a crucial role in cell-cell communication ${ }^{31,32)}$. EV includes microvesicles (MVs), exosome, and apoptotic bodies ${ }^{13,33)}$. MVs $(100-1,000 \mathrm{~nm})$ is originated from the outward membrane budding and released directly from the plasma membrane, whereas the exosomes (30-100 nm) originate from the inward budding of multivesicular bodies (MVB) that are formed as intraluminal vesicles (ILVs) and are re-

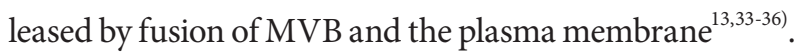
The apoptotic bodies (500-4,000 $\mathrm{nm}$ ) are usually generated by cells undergoing cell death ${ }^{37)}$.

A number of early studies have shown therapeutic outcomes of MSC-derived EV from the improvement of renal failure $^{38-44)}$, where the regenerative effects are mediated by various molecules such as protein, messenger RNA (mRNA), and micro RNA (miRNA) ${ }^{13)}$. The introduction of insulin growth factor 1 receptor (IGF1R) mRNA enriched MSCderived EVs showed improvement in cell proliferation, when co-incubated with damaged proximal renal tubular epithelial cells in an in vitro cisplatin-induced AKI model, suggesting of the renoprotective effects ${ }^{43)}$. In an ischemiareperfusion injury (IRI) model using rats, Gatti et al. demonstrated the therapeutic outcomes of MVs from human BM-MSC on the improvement of renal functions, where the beneficial effects are believed to be attributed to the transfer of RNA for renal cell activation ${ }^{40)}$. Another study by Bruno et al. emphasized the transfer of mRNA and showed that the administration of MSC-derived MVs improved the survival rate of mice with the glycerol-induced $\mathrm{AKI}^{38)}$. The therapeutic mechanism is believed to be due to the proliferation of tubular cells by the administrated MVs, of which MV RNA was internalized into the targeting cells. However, abolishing of MVs with RNase abrogated the protective results, suggesting RNA dependent biological effects. This study suggests that the mRNA transfer through MV internalization to the targeting cells could be considered as a new therapeutic platform for the treatment of renal failure ${ }^{38)}$. Interestingly, MSC-EVs derived from different cell origin have heterogeneous mRNA contents ${ }^{13)}$. In human bone marrow MSC-derived EVs, mRNAs for transcription (e.g. TCFP2, RAX2, IRF6), cell cycle regulation (e.g. SENP2, RBL1, CDC14B), immune regulation (e.g. IL1RN, MT1X, CRLF1), extracellular matrix remodeling (e.g. COL4A2, IBSP), cytoskeleton (e.g. DDN, MSN, CTNNA1), cell differentiation (e.g. RAX2, EPX, SCNN1G) and hematopoietin (e.g., HK3, EPX) were identified ${ }^{13,38,39)}$. On the other hand, adipose tissue-derived MSCs-EVs contained mRNAs for transcription (e.g., MDFIC, POU3F1), angiogenesis (e.g., HES1, TCF4), adipogenesis (e.g., CEBPA, KLF7), Golgi apparatus gene (ARRB1, GOLGA4), and TGF- $\beta$ signaling (e.g., TGFB1, TGFB3) ${ }^{39,44)}$. These findings suggest that appropriate selection of the secretome-derived EVs is needed for targeting treatment of specific conditions.

In addition to the beneficial effects of mRNA from EVs, several studies have confirmed the potential regenerative effects of miRNA in the MSC-derived EVs ${ }^{45-47)}$. miRNAs are known to regulate $30-70 \%$ of mRNA expressions at the post-transcriptional level ${ }^{13,45,48)}$ and considered as a key contributor to the overall biological functions and therapeutic features of EV (exosome) ${ }^{43)}$. In an in vitro model of IRI induced by ATP depletion, miR-410, miR-495, miR$548 c-5 p$, and let-7a improved the renal recovery by downregulation of mRNA coding associated with apoptosis, cytoskeleton reorganization and hypoxia, such as CASP3 and 7, SHC1 and SMAD4 ${ }^{39,46)}$. The up-regulation of miR375, miR-548c-5p, and miR-561 down-regulates SHC1, impeding the pro-survival EGFR-ras-ERK pathway ${ }^{44,47)}$. In a unilateral ureteral obstruction (UUO) model, Wang et al. miRNA-let-7c in MSC derived EVs improved renal injury and decreased fibrotic markers, such as collagen IV IVa1, TGF- $\beta 1$, and TGF $\beta$ R1[49]. In addition, miR-29b, which contributes in epithelial-mesenchymal transition (EMT), downregulates angiotensin II-induced EMT via $\mathrm{PI} 3 \mathrm{k} / \mathrm{AKT}$ signaling pathway to target renal interstitial fibrosis $^{50)}$ and also miR-21 was reported to protect the epithelial cell from IRI by preventing cell apoptosis and dendritic cell maturation ${ }^{51)}$. Overexpression of the therapeutic 
miRNA such as miR-29b and miR-21 in the EVs could be a potential therapeutic for improving renal function ${ }^{50,51)}$.

\section{Secretome derived from other cell types}

While most of the secretome studies have focused on MSC as a source of secretome, several studies have reported that different types of therapeutic cells could be used as secretome sources. As noted above, primary renal cells demonstrated therapeutic effects on the improvement of renal functions ${ }^{4,5,52)}$. Dominguez et al. showed the therapeutic effects of primary renal cell-derived secretome on kidney improvement ${ }^{53)}$. They collected EV compartments from rat renal tubular cells and intravenously injected the $\mathrm{EV}$ into a renal ischemia model in rats. The injection of EV significantly improved renal functions and reduced tubular damages and fibrosis. They suggested that the therapeutic effects by the EV therapy are likely due to a reduction of the large renal transcriptome drift observed after ischemia ${ }^{53)}$.

Secretomes derived from embryonic stem cells (ESC), and induced pluripotent stem cell (iPSC) have also been studied. Several reports using ESC-derived secretome demonstrated immunosuppression and proliferation ability, and have suggested that this system may be used as a therapeutic option for renal treatment ${ }^{54,55)}$. One study performed by van Koppen et al. used a rat CKD model to examine the therapeutic outcomes of ESC-derived secretome ${ }^{55)}$. Intravenous injection into the CKD rats showed that human embryonic MSC-derived secretome decreased the progression of CKD and improved tubular and glomerular injury. They suggested that the therapeutic effect is likely due to enhanced endothelial cell regeneration through active DNA damage repair ${ }^{55)}$. Interestingly, they also mentioned that the exosome only treatment from the MSC-derived secretome was not effective in the improvement of renal function. This finding suggests that incorporation of soluble factors and $\mathrm{EV}$ is essential to facilitate maximized therapeutic outcomes from the $\mathrm{CKD}^{55)}$.

Likewise, iPSC-derived secretome has shown to have antioxidant, anti-inflammatory, and anti-apoptotic effects ${ }^{56,56)}$. A study by Li et al. showed anti-inflammatory effects of the iPSC-derived secretome. They showed the suppression of macrophage inflammatory protein-2, malondialdehyde, and increased total glutathione and inhibition of PI3K/Akt pathway ${ }^{57)}$. Furthermore, the iPSC-derived sec- retome significantly increased the expression of interferon gamma-induced protein-10 (IP-10) and mRNA, mitigating the tissue damage. These results suggest a protective effect of iPSC-derived secretome through a paracrine regulatory mechanism. In accordance with the previous studies, Tarng et al. have discovered that iPSC-derived secretome facilitated the significant improvement of the renal condition and reduced apoptosis through intraperitoneal (IP) administration $^{58)}$. A decrease in reactive oxygen species (ROS) production and inflammatory cytokines expression was observed in the iPSC secretome-treated group. They suggested that improvement of renal function is due to down-regulation of the oxidative stress-related pathway in the renal ischemia ${ }^{58)}$.

Based on the results that angiogenic effects of the MSC, ESC, and iPSC-derived secretomes are able to improve renal function, endothelial progenitor cells (EPC) appear to be a promising secretome source, since EPC was found to improve angiogenesis and neovasculogenesis ${ }^{59-62)}$. Recent studies showed that EPC-derived secretome contains pro-angiogenetic, anti-apoptotic, and antioxidant features. Urbich et al. examined the expression profile of angiogenic growth factors such as VEGF-A, VEGF-B, SDF-1, and IGF1 in different endothelial cell types, and found that EPC showed higher levels of the angiogenic ability than that of mature endothelial cells, such as human umbilical vein endothelial cells (HUVEC) or human microvascular endothelial cells (HMVEC) as well as monocyte ${ }^{59)}$. The release of soluble factors was significantly higher in EPC as compared with other cells. Furthermore, EPC-derived secretome increased the migration of endothelial cells. This study concludes that the release of various factors from EPC enhances the survival and functions of cells in a paracrine manner, expediting angiogenesis and regeneration of tissues. Another study by Yang et al. examined the effect of antioxidant of EPC features by treating HUVEC with EPC secretome under a hypoxic condition ${ }^{60)}$. The EPCsecretome treated HUVEC showed a significant reduction in apoptosis and improvement in tubular formation, which exerts the anti-oxidative effect of the EPC-secretome. Cantaluppi et al. tested the therapeutic effects of EPCsecretome components on the improvement of renal functions in an AKI model using rats ${ }^{61)}$. They intravenously injected miRNA-enriched microvesicles in the AKI rats 
and found that the injected microvesicles were localized within the peritubular capillary and tubular cells. Furthermore, they demonstrated that the delivered microvesicles induced tubular cell proliferation, reduced apoptosis, and amelioration of fibrosis. In a miRNA depletion assay, they confirmed that the renoprotective effect is due to the bioactive miRNA in the microvesicle that contributes to the reprogramming of host renal cells for the renal functions. In a subsequent study, Cantaluppi et al. also demonstrated that EVs derived from EPCs exert a protective effect in Thy 1.1 glomerulonephritis by inhibiting complement-mediated renal injury ${ }^{62)}$.

\section{Secretome delivery for renal treatment}

While cell secretome has shown to improve renal function in multiple studies, the delivery method has been a limitation to achieve maximum therapeutic effects of the secretome. For instance, Xing et al. reported that MSCsecretome was not effective in improving renal function in an IRI kidney injury model in mice, which may be due to inefficient delivery of the secretome in a low concentration state $^{63)}$. Similarly, Abedi et al. observed partial tissue regeneration when MSC-derived secretome was intraperitoneally injected into animals with kidney failure ${ }^{27)}$. In either study, the injected trophic factors in the secretome may have lost their biological activity within a short time, likely due to a high diffusion rate and short half-life following injection ${ }^{64-66)}$. To address this issue, the controlled release of secretome factors into the injured site is necessary to achieve improved therapeutic effects.

Drug delivery system has been developed as a promising option to facilitate a controlled and sustained release of bioactive factors to exert maximized outcomes in tissue regeneration $^{67-70)}$. Delivery vehicles, including natural and synthetic materials, have been designed to physically encapsulate target factors or immobilize the factors on the vehicles, thereby protecting them from the effect of enzymatic environment and prolonging therapeutic effects in $v^{\text {vivo }}{ }^{67-70)}$. As a delivery vehicle, hydrogel systems have been widely used, and a combination of hydrogel with the secretome has been proposed as a possible platform due to its versatility required for biological use $\mathrm{e}^{71)}$. In several studies, secretome encapsulated in the hydrogel was used by directly adding hydrogel-initiating materials into the cell culture. In a study, Bakota et al. developed an injectable multidomain peptide (MDP) nanofiber hydrogel system for delivering secretome ${ }^{72)}$. The MDF hydrogel is designed to soak secretome factors when placed into the ESC cell culture. The self-assembled MDP hydrogel loaded with stem cellderived secretome demonstrated stability over time, sheer thinning tolerance, allowing for targeting release condition that can be easily delivered through needle injection. In a release kinetic study in mice, the administered hydrogels with secretome through an intraperitoneal injection remained localized for 24 hours, indicating the effectiveness of secretome delivery via MDP hydrogel system. In a further study, Wang et al. examined whether the MDP nanofiber hydrogel system was able to exert reno-protective effects using lipopolysaccharide (LPS) induced both an in vitro and an in vivo model ${ }^{73)}$. LPS exposure resulted in a significant increase in activation of caspase-3, which mediates apoptosis ${ }^{74)}$, and RhoA/Rho kinase, which involves in cell permeability and apoptosis ${ }^{75)}$, but the presence of preconditioned nanofibers reduced cell apoptosis in an in vitro by preventing these activations. The introduction of preconditioned nanofibers, which were developed by combining stem cell with the nanofibers, improved LPSinduced kidney in both an in vitro and an in vivo study. In an in vivo study using LPS-induced kidney injury, a rise in serum blood urea nitrogen (BUN) and creatinine levels in the LPS injected mice was significantly reduced when treated with nanofibers hydrogel with secretome. They suggested that the nanofiber hydrogel system could be used as a secretome delivery platform for the treatment of renal failure. More recently, Waters et al. developed a nanocomposite hydrogel system to facilitate secretome-based a dual-action therapy ${ }^{76)}$. They used 2D synthetic nanoclay material LAPONITE ${ }^{\circledast}$ nanosilicates to form a complex with growth factors in the secretome ${ }^{76)}$. By UV crosslinking of mixtures of nanoclay-secretome and gelatin methacrylate (GelMA), they were able to load the crosslinked complex of nanoclay-growth factors within a nanocomposite hydrogel that potentially deliver secretome released from human MSC. The nanoclay hydrogel showed a controlled release of growth factors such as VEGF and FGF2, by slowing secretome release overtime in an in vitro study. 
Comparing with nanoclay hydrogel without secretome, the angiogenesis potential of the hydrogel with secretome was confirmed by a significant increase in endothelial cell proliferation and migration observed in a microchannel migration assay and the inhibition of apoptosis was observed in a TdT-mediated dUTP nick end labeling (TUNEL) assay. They suggest that the nanoclay hydrogel system containing pro-angiogenesis and tissue-protective ability has the potential to provide a valuable therapeutic platform for tissue regeneration.

Recently, our group developed a clinically relevant hydrogel-based delivery system to efficiently deliver human placental stem cells (hPSCs)-derived secretome to treat kidney ischemia in rats ${ }^{77)}$. Unlike the previous three studies where hydrogel formation with cell secretome occurs on the cell culture in situ through a one-step process ${ }^{72,73,76)}$, our approach consists of two steps; 1) collection of cell secretome from cell culture; 2) incorporation of the collected secretome into a hydrogel system. Thus, our strategy enables for an "off-the-shelf" therapy and efficient quality control of the secretome by utilizing cryopreserved secretome. As the clinically relevant hydrogel source, plateletrice plasma (PRP) hydrogel was used since PRP is biocompatible and safe for clinical applications ${ }^{78,79)}$. Furthermore, autologous PRP obtained from the patient is therapeutically beneficial to minimize immune response as compared with that of an allogeneic or xenogeneic source. In our study, we demonstrated that hPSC-derived secretome contained the pro-proliferative and anti-apoptotic ability for endothelial and primary human tubular cells. A release kinetics study showed that incorporation of secretome within the PRP gel system facilitated controlled release of secretome factors in an in vitro and in vivo study. When the PRP encapsulated secretome was tested in an IRI injury model in rats, the secretome+PRP treated group showed significantly lower serum creatinine $(\mathrm{Cr})$ and neutrophil gelatinase-associated lipocalin (NGAL) levels than that of other groups, demonstrating improvement in renal function compared with other controls. We confirmed that the therapeutic outcomes by the delivery of secretome through PRP gel are due to minimized renal tissue damages through anti-apoptotic and pro-angiogenic capability. Our results suggest that secretome encapsulation with PRP gel could be an effective approach for the controlled delivery of secretomes for re- covery of damaged kidneys.

\section{Perspective}

While the cell-derived secretome approach demonstrates promising reno-therapeutic outcomes in pre-clinical and clinical studies $^{80)}$, a number of challenges need to be addressed before using this modality for clinical translation. A major issue in the use of secretome is attributed to the unidentified characteristics of the cell-secreted factors ${ }^{7}$. Further studies are needed to characterize better and define the secreting factors, which allows for improved control and regulation for clinical translation. Furthermore, clinical efficacy and indication need to be assessed in welldesigned and controlled clinical trials ${ }^{81)}$.

In the manufacturing process for commercialization, production, and concentration of secreted molecules in quantities sufficient for clinical administration are also challenging, in terms of efficient therapeutic effects. A recent study involving the EV production on a large scale ${ }^{36)}$ would enable efficient delivery of sufficient quantities of EV containing miRNAs could be adapted for clinical translation. Also, it is important to note that differential expression of specific molecules in the secretomes might result in different level of beneficial outcomes. For example, Pires et al. demonstrated different profiles of secretomes from BM-MSC, adipose derived cells (ASC), human umbilical cord perivascular cells (HUCPVCs) using a proteomic analysis $^{82)}$. Interestingly, secretion profiles of the specific secretomes from BM-MSC allowed more anti-oxidative stress than that of ASC and HUCPVCs. Interestingly, BMMSC and HUCPVCs showed better anti-apoptotic properties than ASCs, while HUCPVCs is not appropriate as anti-scarring agent. Therefore, appropriate selection of the secretome is needed to maximize therapeutic outcomes for efficient renal treatment.

In addition, the engineering strategy of secretome components has a significant potential to develop a treatment for kidney damage efficiently. For example, engineering of exosome as a therapeutic cue may be a viable approach to improve kidney function and promote regeneration, where exosome could be modified to load therapeutic drugs passively or the exosome surface can be anchored with the 
targeting moieties to efficiently home to the repair site ${ }^{83)}$. Such engineering strategies would be beneficial to enhance therapeutic outcomes compared with the naïve type.

\section{References}

1. Ko IK, Yoo JJ, Atala A. Regenerative Medicine Approaches for the Kidney, Principles of Regenerative Medicine (Third Edition), 2019, 1165-1177. Academic Press. In: Principles of Regenerative Medicine (Third Edition).

2. Moon KH, Ko IK, Yoo JJ, Atala A. Kidney diseases and tissue engineering. Methods 2016;99:112-9.

3. Cho KS, Ko IK, Yoo JJ. Bioactive Compounds for the Treatment of Renal Disease. Yonsei Med J 2018;59:1015-25.

4. Stenvinkel P, Wadström J, Bertram T, Detwiler R, Gerber D, Brismar TB, et al. Implantation of Autologous Selected Renal Cells in Diabetic Chronic Kidney Disease Stages 3 and 4-Clinical Experience of a "First in Human" Study. Kidney Int Rep 2016;1:105-13.

5. Yamaleyeva LM, Guimaraes-Souza NK, Krane LS, Agcaoili S, Gyabaah K, Atala A, et al. Cell Therapy with Human Renal Cell Cultures Containing Erythropoietin-Positive Cells Improves Chronic Kidney Injury. STEM CELLS Transl Med 2012;1:373-83.

6. Maeshima A, Nakasatomi M, Nojima Y. Regenerative Medicine for the Kidney: Renotropic Factors, Renal Stem/Progenitor Cells, and Stem Cell Therapy. BioMed Res Int 2014;2014:1-10.

7. Tran C, Damaser MS. Stem cells as drug delivery methods: Application of stem cell secretome for regeneration. Adv Drug Deliv Rev 2015;82-83:1-11.

8. Herberts CA, Kwa MS, Hermsen HP. Risk factors in the development of stem cell therapy. J Transl Med 2011;9:29.

9. Kim HO, Choi S-M, Kim H-S. Mesenchymal stem cell-derived secretome and microvesicles as a cell-free therapeutics for neurodegenerative disorders. Tissue Eng Regen Med 2013;10:93-101.

10. Beer L, Mildner M, Ankersmit HJ. Cell secretome based drug substances in regenerative medicine: when regulatory affairs meet basic science. Ann Transl Med 2017; 5:170.

11. Sun DZ, Abelson B, Babbar P, Damaser MS. Harnessing the mesenchymal stem cell secretome for regenerative urology. Nat Rev Urol 2019;16:363-75.

12. Pittenger MF. Multilineage Potential of Adult Human Mesenchymal Stem Cells. Science 1999;284:143-7.

13. Tsuji K, Kitamura S, Wada J. Secretomes from Mesenchymal Stem Cells against Acute Kidney Injury: Possible Heterogeneity. Stem Cells International 2018;1-14.

14. Maguire G. Stem cell therapy without the cells. Commun Integr Biol 2013;6.

15. Chen L, Tredget EE, Wu PYG, Wu Y. Paracrine Factors of Mesenchymal Stem Cells Recruit Macrophages and Endothelial Lineage Cells and Enhance Wound Healing. PLoS One 2008:3:e1886.
16. Ciapetti G, Baldini DG and N. The Combined Use of Mesenchymal Stromal Cells and Scaffolds for Bone Repair. Curr Pharm Des 2012;18:1796-820.

17. Senger DR. Vascular Endothelial Growth Factor: Much More than an Angiogenesis Factor. Mol Biol Cell 2010;21:377-9.

18. Leung DW, Cachianes G, Kuang WJ, Goeddel DV, Ferrara N. Vascular endothelial growth factor is a secreted angiogenic mitogen. Science 1989;246:1306-9.

19. Kinnaird T, Stabile E, Burnett MS, Shou M, Lee CW, Barr S, et al. Local Delivery of Marrow-Derived Stromal Cells Augments Collateral Perfusion Through Paracrine Mechanisms. Circulation 2004;109:1543-9.

20. Tögel F, Weiss K, Yang Y, Hu Z, Zhang P, Westenfelder C. Vasculotropic, paracrine actions of infused mesenchymal stem cells are important to the recovery from acute kidney injury. Am J PhysiolRen Physiol 2007;292:F1626-35.

21. Rota C, Imberti B, Pozzobon M, Piccoli M, De Coppi P, Atala A, et al. Human Amniotic Fluid Stem Cell Preconditioning Improves Their Regenerative Potential. Stem Cells Dev 2012;21:1911-23.

22. Takahashi M, Li T-S, Suzuki R, Kobayashi T, Ito H, Ikeda Y, et al. Cytokines produced by bone marrow cells can contribute to functional improvement of the infarcted heart by protecting cardiomyocytes from ischemic injury. Am J Physiol-Heart Circ Physiol 2006;291:H886-93.

23. Bai L, Lennon D, Eaton V, Maier K, Caplan A, Miller S, et al. Human Bone Marrow-derived Mesenchymal Stem Cells Induce Th2Polarized Immune Response and Promote Endogenous Repair in Animal Models of Multiple Sclerosis. Glia 2009;57:1192-203.

24. Duffy MM, Pindjakova J, Hanley SA, McCarthy C, Weidhofer GA, Sweeney EM, et al. Mesenchymal stem cell inhibition of T-helper 17 cell- differentiation is triggered by cell-cell contact and mediated by prostaglandin E2 via the EP4 receptor. Eur J Immunol 2011:41:2840-51.

25. Luz-Crawford P, Djouad F, Toupet K, Bony C, Franquesa M, Hoogduijn MJ, et al. Mesenchymal Stem Cell-Derived Interleukin 1 Receptor Antagonist Promotes Macrophage Polarization and Inhibits B Cell Differentiation. STEM CELLS 2016;34:483-92.

26. Sharma R, Kinsey GR. Regulatory T cells in acute and chronic kidney diseases. Am J Physiol-Ren Physiol 2018;314:F679-98.

27. Abedi A, Azarnia M, Zahvarehy MJ, Foroutan T, Golestani S. Effect of Different Times of Intraperitoneal Injections of Human Bone Marrow Mesenchymal Stem Cell Conditioned Medium on Gentamicin-Induced Acute Kidney Injury. Urol J 2016;13:2707-16.

28. Da Silva AF, Silva K, Reis LA, Teixeira VPC, Schor N. Bone MarrowDerived Mesenchymal Stem Cells and Their Conditioned Medium Attenuate Fibrosis in an Irreversible Model of Unilateral Ureteral Obstruction. Cell Transplant 2015;24:2657-66.

29. Liu B, Ding F-X, Liu Y, Xiong G, Lin T, He D-W, et al. Human umbilical cord-derived mesenchymal stem cells conditioned medium attenuate interstitial fibrosis and stimulate the repair of tubular epithelial cells in an irreversible model of unilateral ureteral obstruction: Conditioned medium in renal fibrosis. Nephrology 
2018;23:728-36

30. Bollini S, Gentili C, Tasso R, Cancedda R. The Regenerative Role of the Fetal and Adult Stem Cell Secretome. J Clin Med 2013;2:30227.

31. Riazifar M, Pone EJ, Lötvall J, Zhao W. Stem Cell Extracellular Vesicles: Extended Messages of Regeneration. Annu Rev Pharmacol Toxicol 2017;57:125-54.

32. Yáñez-Mó M, Siljander PR-M, Andreu Z, Zavec AB, Borràs FE, Buzas El, et al. Biological properties of extracellular vesicles and their physiological functions. J Extracell Vesicles 2015;4:27066.

33. Rad F, Pourfathollah AA, Yari F, Mohammadi S, Kheirandish M. Microvesicles preparation from mesenchymal stem cells. Med J Islam Repub Iran 2016;30:398.

34. Record M, Silvente-Poirot S, Poirot M, Wakelam MJO. Extracellular vesicles: lipids as key components of their biogenesis and functions. J Lipid Res 2018;59:1316-24.

35. Colombo M, Raposo G, Théry C. Biogenesis, Secretion, and Intercellular Interactions of Exosomes and Other Extracellular Vesicles. Annu Rev Cell Dev Biol 2014;30:255-89.

36. Yoo KW, Li N, Makani V, Singh RN, Atala A, Lu B. Large-Scale Preparation of Extracellular Vesicles Enriched with Specific microRNA. Tissue Eng Part C Methods 2018;24:637-44.

37. Akers JC, Gonda D, Kim R, Carter BS, Chen CC. Biogenesis of extracellular vesicles (EV): exosomes, microvesicles, retrovirus-like vesicles, and apoptotic bodies. J Neurooncol 2013;113:1-11.

38. Bruno S, Grange C, Deregibus MC, Calogero RA, Saviozzi S, Collino F, et al. Mesenchymal Stem Cell-Derived Microvesicles Protect Against Acute Tubular Injury. J Am Soc Nephrol 2009;20:1053-67.

39. Nargesi AA, Lerman LO, Eirin A. Mesenchymal stem cell-derived extracellular vesicles for renal repair. Curr Gene Ther 2017;17:2942.

40. Gatti S, Bruno S, Deregibus MC, Sordi A, Cantaluppi V, Tetta C, et al. Microvesicles derived from human adult mesenchymal stem cells protect against ischaemia-reperfusion-induced acute and chronic kidney injury. Nephrol Dial Transplant Off Publ Eur Dial Transpl Assoc-Eur Ren Assoc 2011;26:1474-83.

41. Reis LA, Borges FT, Simões MJ, Borges AA, Sinigaglia-Coimbra R, Schor N. Bone marrow-derived mesenchymal stem cells repaired but did not prevent gentamicin-induced acute kidney injury through paracrine effects in rats. PloS One 2012;7:e44092.

42. Bruno S, Grange C, Collino F, Deregibus MC, Cantaluppi V, Biancone L, et al. Microvesicles Derived from Mesenchymal Stem Cells Enhance Survival in a Lethal Model of Acute Kidney Injury PLOS ONE 2012;7:33115.

43. Tomasoni S, Longaretti L, Rota C, Morigi M, Conti S, Gotti E, et al. Transfer of Growth Factor Receptor mRNA Via Exosomes Unravels the Regenerative Effect of Mesenchymal Stem Cells. Stem Cells Dev 2013;22:772-80.

44. Eirin A, Riester SM, Zhu XY, Tang H, Evans JM, O'Brien D, et al. MicroRNA and mRNA cargo of extracellular vesicles from porcine adipose tissue-derived mesenchymal stem cells. Gene 2014;551: $55-64$.
45. Ferguson SW, Wang J, Lee CJ, Liu M, Neelamegham S, Canty JM, et al. The microRNA regulatory landscape of MSC-derived exosomes: a systems view. Sci Rep 2018;8.

46. Lindoso RS, Collino F, Bruno S, Araujo DS, Sant'Anna JF, Tetta C, et al. Extracellular Vesicles Released from Mesenchymal Stromal Cells Modulate miRNA in Renal Tubular Cells and Inhibit ATP Depletion Injury. Stem Cells Dev 2014;23:1809-19.

47. Meng X-M, Huang XR, Xiao J, Chung ACK, Qin W, Chen H, et al. Disruption of Smad4 impairs TGF- $\beta / S$ mad3 and Smad7 transcriptional regulation during renal inflammation and fibrosis in vivo and in vitro. Kidney Int 2012;81:266-79.

48. Lu J, Clark AG. Impact of microRNA regulation on variation in human gene expression. Genome Res. 2012;22:1243-54.

49. Wang B, Yao K, Huuskes BM, Shen H-H, Zhuang J, Godson C, et al. Mesenchymal Stem Cells Deliver Exogenous MicroRNA-let7c via Exosomes to Attenuate Renal Fibrosis. Mol Ther 2016;24:1290301.

50. Hu H, Hu S, Xu S, Gao Y, Zeng F. miR-29b regulates Ang II-induced EMT of rat renal tubular epithelial cells via targeting PI3K/AKT signaling pathway. Int J Mol Med Athens 2018;42453-60.

51. Song N, Song N, Song N, Song N, Song N, Zhang T, et al. miR-21 Protects Against Ischemia/Reperfusion-Induced Acute Kidney Injury by Preventing Epithelial Cell Apoptosis and Inhibiting Dendritic Cell Maturation. Front Physiol 2018;9.

52. George SK, Abolbashari M, Jackson JD, Aboushwareb T, Atala A, Yoo JJ. Potential Use of Autologous Renal Cells from Diseased Kidneys for the Treatment of Renal Failure. PLOS ONE 2016;11: e0164997.

53. Dominguez JH, Liu Y, Gao H, Dominguez JM, Xie D, Kelly KJ. Renal Tubular Cell-Derived Extracellular Vesicles Accelerate the Recovery of Established Renal Ischemia Reperfusion Injury. J Am Soc Nephrol 2017;28:3533-44.

54. Drukker M, Katchman H, Katz G, Even-Tov Friedman S, Shezen E, Hornstein E, et al. Human Embryonic Stem Cells and Their Differentiated Derivatives Are Less Susceptible to Immune Rejection Than Adult Cells. Stem Cells 2006;24:221-9.

55. Koppen A van, Joles JA, Balkom BWM van, Lim SK, de Kleijn D, Giles RH, et al. Human Embryonic Mesenchymal Stem Cell-Derived Conditioned Medium Rescues Kidney Function in Rats with Established Chronic Kidney Disease. PLoS One San Franc 2012;7: e38746.

56. Lee PY, Chien Y, Chiou GY, Lin CH, Chiou CH, Tarng DC. Induced Pluripotent Stem Cells without c-Myc Attenuate Acute Kidney Injury via Downregulating the Signaling of Oxidative Stress and Inflammation in Ischemia-Reperfusion Rats. Cell Transplant 2012;21:2569-85.

57. Li LF, Liu YY, Yang CT, Chien Y, Twu NF, Wang ML, et al. Improvement of ventilator-induced lung injury by IPS cell-derived conditioned medium via inhibition of PI3K/Akt pathway and IP10-dependent paracrine regulation. Biomaterials 2013;34:78-91.

58. Tarng DC, Tseng WC, Lee PY, Chiou SH, Hsieh SL. Induced Pluripotent Stem Cell-Derived Conditioned Medium Attenuates Acute 
Kidney Injury by Downregulating the Oxidative Stress-Related Pathway in Ischemia-Reperfusion Rats. Cell Transplant 2016;25: 517-30.

59. Urbich C, Aicher A, Heeschen C, Dernbach E, Hofmann W, Zeiher A, et al. Soluble factors released by endothelial progenitor cells promote migration of endothelial cells and cardiac resident progenitor cells. J Mol Cell Cardiol 2005;39:733-42.

60. Yang Z, von Ballmoos MW, Faessler D, Voelzmann J, Ortmann J, Diehm N, et al. Paracrine factors secreted by endothelial progenitor cells prevent oxidative stress-induced apoptosis of mature endothelial cells. Atherosclerosis 2010;211:103-9.

61. Cantaluppi V, Gatti S, Medica D, Figliolini F, Bruno S, Deregibus $M C$, et al. Microvesicles derived from endothelial progenitor cells protect the kidney from ischemia-reperfusion injury by microRNAdependent reprogramming of resident renal cells. Kidney Int 2012;82:412-27.

62. Cantaluppi V, Medica D, Mannari C, Stiaccini G, Figliolini F, Dellepiane $\mathrm{S}$, et al. Endothelial progenitor cell-derived extracellular vesicles protect from complement-mediated mesangial injury in experimental anti-Thy1.1 glomerulonephritis. Nephrol Dial Transplant 2015;30:410-22.

63. Xing L, Cui R, Peng L, Ma J, Chen X, Xie R-J, et al. Mesenchymal stem cells, not conditioned medium, contribute to kidney repair after ischemia-reperfusion injury. Stem Cell Res Ther 2014;5.

64. Pawitan JA. Prospect of Stem Cell Conditioned Medium in Regenerative Medicine. BioMed Res Int N Y 2014;14.

65. Yde P, Mengel B, Jensen MH, Krishna S, Trusina A. Modeling the NF-KB mediated inflammatory response predicts cytokine waves in tissue. BMC Syst Biol 2011;5:115.

66. Khosravi A, Cutler CM, Kelly MH, Chang R, Royal RE, Sherry RM, et al. Determination of the Elimination Half-Life of Fibroblast Growth Factor-23. J Clin Endocrinol Metab 2007;92:2374-7.

67. Zern BJ, Chu H, Wang Y. Control Growth Factor Release Using a Self-Assembled [polycation:heparin] Complex. PLoS ONE 2010; 5:e11017.

68. Richardson TP, Peters MC, Ennett AB, Mooney DJ. Polymeric system for dual growth factor delivery. Nat Biotechnol 2001;19: 1029-34.

69. Chen F-M, Zhang M, Wu Z-F. Toward delivery of multiple growth factors in tissue engineering. Biomaterials 2010;31:6279-308.

70. Ko IK, Ju YM, Chen T, Atala A, Yoo JJ, Lee SJ. Combined systemic and local delivery of stem cell inducing/recruiting factors for in situ tissue regeneration. FASEB J 2012;26:158-68.

71. Hule RA, Nagarkar RP, Altunbas A, Ramay HR, Branco MC, Sch- neider JP, et al. Correlations between structure, material properties and bioproperties in self-assembled $\beta$-hairpin peptide hydrogels. Faraday Discuss 2008;139:251.

72. Bakota EL, Wang Y, Danesh FR, Hartgerink JD. Injectable Multidomain Peptide Nanofiber Hydrogel as a Delivery Agent for Stem Cell Secretome. Biomacromolecules 2011;12:1651-7.

73. Wang Y, Bakota E, Chang BHJ, Entman M, Hartgerink JD, Danesh FR. Peptide Nanofibers Preconditioned with Stem Cell Secretome Are Renoprotective. J Am Soc Nephrol 2011;22:704-17.

74. Porter AG, Jänicke RU. Emerging roles of caspase-3 in apoptosis. Cell Death Differ 1999;6:99-104.

75. Zeng L, Xu H, Chew T-L, Eng E, Sadeghi MM, Adler S, et al. HMG CoA reductase inhibition modulates VEGF-induced endothelial cell hyperpermeability by preventing RhoA activation and myosin regulatory light chain phosphorylation. FASEB J 2005;19:184552.

76. Waters R, Pacelli S, Maloney R, Medhi I, Ahmed RPH, Paul A. Stem cell secretome-rich nanoclay hydrogel: a dual action therapy for cardiovascular regeneration. Nanoscale 2016;8:7371-6.

77. Yim HE, Kim DS, Chung HC, Shing B, Moon KH, George SK, et al. Controlled Delivery of Stem Cell-Derived Trophic Factors Accelerates Kidney Repair After Renal Ischemia-Reperfusion Injury in Rats. Stem Cells Transl Med 2019;8:959-70.

78. Patel AN, Selzman CH, Kumpati GS, McKellar SH, Bull DA. Evaluation of autologous platelet rich plasma for cardiac surgery: outcome analysis of 2000 patients. J Cardiothorac Surg 2016;11:62.

79. Li W, Enomoto M, Ukegawa M, Hirai T, Sotome S, Wakabayashi Y, et al. Subcutaneous Injections of Platelet-Rich Plasma into Skin Flaps Modulate Proangiogenic Gene Expression and Improve Survival Rates: Plast Reconstr Surg 2012;129:858-66.

80. Nassar W, El-Ansary M, Sabry D, Mostafa MA, Fayad T, Kotb E, et al. Umbilical cord mesenchymal stem cells derived extracellular vesicles can safely ameliorate the progression of chronic kidney diseases. Biomater Res 2016;20.

81. Torres Crigna A, Daniele C, Gamez C, Medina Balbuena S, Pastene DO, Nardozi D, et al. Stem/Stromal Cells for Treatment of Kidney Injuries With Focus on Preclinical Models. Front Med 2018;5.

82. Pires AO, Mendes-Pinheiro B, Teixeira FG, Anjo SI, Ribeiro-Samy S, Gomes ED, et al. Unveiling the Differences of Secretome of Human Bone Marrow Mesenchymal Stem Cells, Adipose TissueDerived Stem Cells, and Human Umbilical Cord Perivascular Cells: A Proteomic Analysis. Stem Cells Dev 2016;25:1073-83.

83. Bruno S, Porta S, Bussolati B. Extracellular vesicles in renal tissue damage and regeneration. Eur J Pharmacol 2016;790:83-91. 